
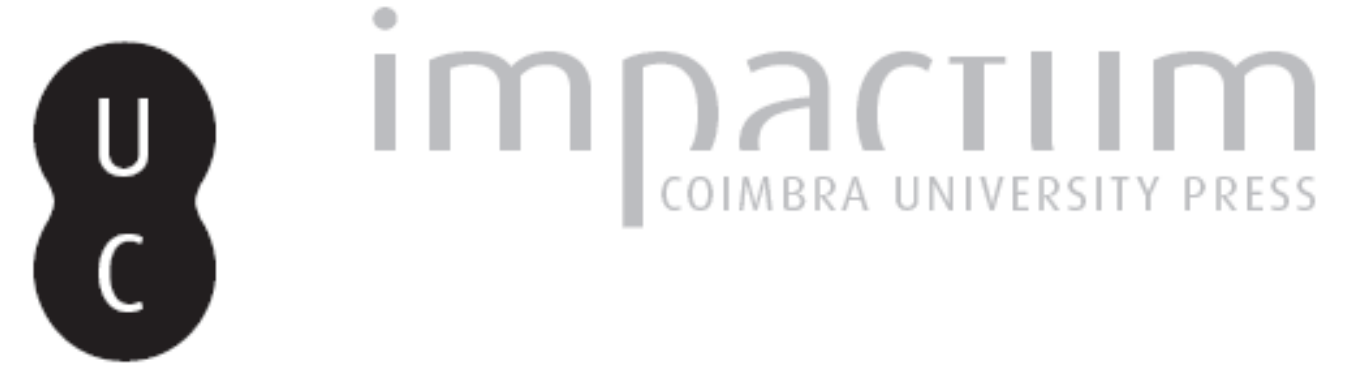

\title{
O problema da representação e a construção do povo: algumas notas sobre a actualidade do debate Schmitt versus Kelsen
}

Autor(es): $\quad$ Magalhães, Pedro T.

Publicado por: Imprensa da Universidade de Coimbra

URL persistente:

URI:http://hdl.handle.net/10316.2/41379

DOI:

DOI:https://doi.org/10.14195/2183-8925_33_19

Accessed : $\quad$ 26-Apr-2023 07:44:25

A navegação consulta e descarregamento dos títulos inseridos nas Bibliotecas Digitais UC Digitalis, UC Pombalina e UC Impactum, pressupõem a aceitação plena e sem reservas dos Termos e Condições de Uso destas Bibliotecas Digitais, disponíveis em https://digitalis.uc.pt/pt-pt/termos.

Conforme exposto nos referidos Termos e Condições de Uso, o descarregamento de títulos de acesso restrito requer uma licença válida de autorização devendo o utilizador aceder ao(s) documento(s) a partir de um endereço de IP da instituição detentora da supramencionada licença.

Ao utilizador é apenas permitido o descarregamento para uso pessoal, pelo que o emprego do(s) título(s) descarregado(s) para outro fim, designadamente comercial, carece de autorização do respetivo autor ou editor da obra.

Na medida em que todas as obras da UC Digitalis se encontram protegidas pelo Código do Direito de Autor e Direitos Conexos e demais legislação aplicável, toda a cópia, parcial ou total, deste documento, nos casos em que é legalmente admitida, deverá conter ou fazer-se acompanhar por este aviso.

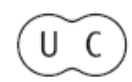



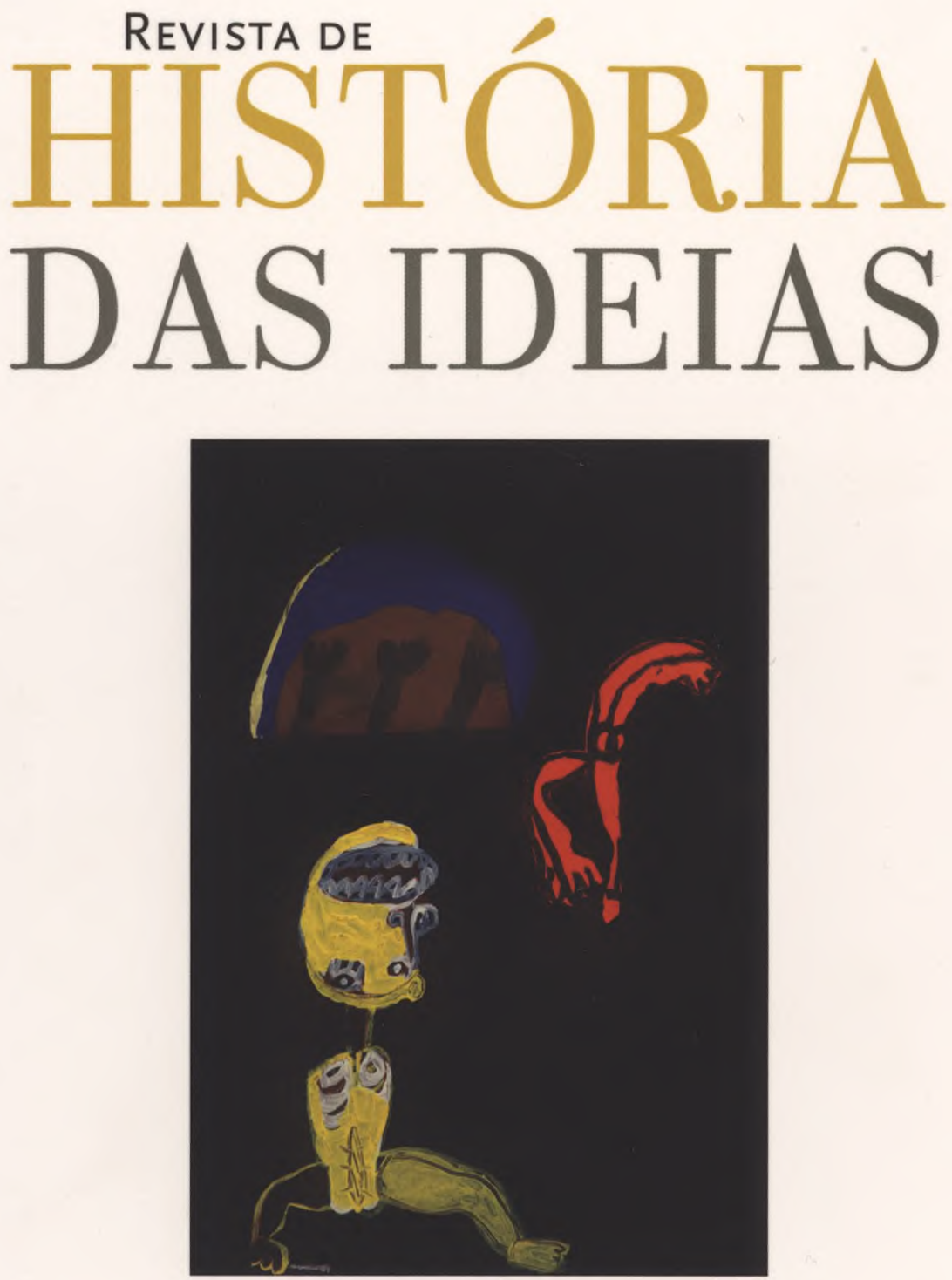

O CORPO

Volume 33, 2012

INSTITUTO de História e TeORIa das IDEIAS

Faculdade de Letras da Universidade de CoImbra 


\section{O PROBLEMA DA REPRESENTAÇÃO \\ E A CONSTRUÇÃO DO POVO. \\ ALGUMAS NOTAS SOBRE A ACTUALIDADE \\ DO DEBATE SCHMITT VERSUS KELSEN**}

\section{Introdução}

O conceito de representação não esteve, ao longo de grande parte da segunda metade do século $X X$, no foco de interesse da teoria política. Este relativo esquecimento pode, à primeira vista, parecer estranho, tendo em conta que nesse período se assistiu a uma expansão extraordinária de regimes que comum e consensualmente se designam por democracias representativas. No entanto, a estranheza dissipa-se, em certa medida, se considerarmos que, na história do pensamento político, desde Hobbes, a representação foi frequentemente pensada em termos não-democráticos ou mesmo em franca oposição à democracia, enquanto, pelo contrário, o pensamento contemporâneo se desenrola praticamente na sua totalidade sob a égide da ideia democrática.

O conceito de representação, em boa verdade, coloca um conjunto de problemas de difícil resolução para o pensamento democrático. Para os autores que se orientam por um ideal de democracia directa,

* Doutorando em Ciência Política, FCSH-UNL.

** O presente artigo baseia-se na dissertação de mestrado do autor, intitulada A Teoria da Representação na Alemanha de Weimar: Schmitt, Kelsen e Leibholz, realizada sob a orientação científica de Pedro Tavares de Almeida e defendida em provas públicas no dia 7 de Novembro de 2011. 
começando por Rousseau, passando pelos saudosistas de uma versão mais ou menos idealizada da polis ateniense (Hannah Arendt) e terminando nos teóricos contemporâneos da democracia dita participativa (Benjamin Barber), a resposta só pode passar por uma rejeição cabal do conceito - não há articulação possível entre democracia e representação. Isso levar-nos-ia, logicamente, a negar aos regimes políticos existentes

- as tais democracias representativas - o estatuto de verdadeiras democracias. Por outro lado, não querendo assumir esta conclusão deveras radical, outras escolas de pensamento procuraram relativizar o alcance do conceito de representação. É o caso, embora com pressupostos muito distintos entre si, tanto da concepção minimal de democracia desenvolvida por Schumpeter e discípulos, como das propostas ético-normativistas de Rawls e Habermas. Ora, o nosso argumento tomará o rumo oposto, procurando sublinhar a centralidade do conceito de representação para o pensamento político em geral e, sobretudo, para a teoria da democracia.

Tomando em consideração que as experiências de democracia directa, na história moderna e contemporânea, são escassas e pouco significativas, e não querendo desposar, à partida, a tese de uma incompatibilidade ontológica entre democracia e representação, julgamos fundamental, em sede de teoria da democracia, o confronto com duas questões no limite inseparáveis: a construção do povo e a sua representação. Com efeito, parece-nos virtualmente impossível pensar a constituição do demos

- isto é, de um sujeito político colectivo que exerce a soberania - sem abordar simultaneamente o problema da representação.

Acercar-nos-emos destas questões recuperando o debate entre dois vultos da teoria do Estado: Carl Schmitt e Hans Kelsen. A reconstrução dessa querela weimariana, após uma secção inicial onde se procurará sintetizar o que de mais relevante a literatura contemporânea tem dito sobre o tema, desenrolar-se-á em três fases. Num primeiro momento, abordaremos o problema na sua dimensão puramente conceptual. Veremos como os conceitos relevantes - povo, representação, vontade comum, Estado - são definidos, tratados e inter-relacionados na obra dos dois autores. Num segundo momento, exploraremos as consequências analíticas de ambas as posições teóricas, ao nível da discussão sobre a crise do parlamentarismo. Finalmente, procuraremos trazer à luz os contributos do debate para o pensamento democrático contemporâneo. A nosso ver, estes residem, sobretudo, na valorização 
das dimensões colectiva e agonística da política democrática, ignoradas ou secundarizadas pelo liberalismo estritamente individualista e consensualista que, nas suas várias declinações, domina boa parte da teoria política contemporânea, tornando-a incapaz de enfrentar os problemas da representação e da formação de um sujeito político colectivo, possuidor de uma vontade comum.

\section{Representação e democracia na teoria política contemporânea: o estado da questão}

Se a rejeição da representação por parte dos defensores da democracia directa não provoca surpresa, o mesmo já não pode ser dito da marginalização do conceito por parte de alguns importantes teóricos da democracia representativa. Efectivamente, causa estranheza que o conceito consensualmente empregue para qualificar os regimes democráticos existentes veja o seu alcance teórico fortemente reduzido, ao ponto de se tornar mero apêndice, mais ou menos incómodo, do termo democracia. Ora, é justamente isso que sucede com os proponentes de uma teoria política de base empírica (Joseph Schumpeter e Anthony Downs, entre outros). Estes menosprezam a ideia de representação, juntamente com os conceitos de bem comum e vontade geral, por a considerarem repleta de subtilezas metafísicas que são irreconciliáveis com uma abordagem tendencialmente descritiva da democracia. Evidentemente, a sua concepção minimal de democracia implica a existência de instituições ditas representativas. Contudo, estas não são pensadas como tal, mas sim como mecanismos que possibilitam a agregação de interesses e preferências individuais através da selecção das elites políticas por via da competição eleitoral.

Por outro lado, o ressurgimento - com a publicação de $A$ Theory of Justice, de John Rawls, no início da década de 1970 - de uma teoria política de índole ético-normativa depara-se com dificuldades distintas na sua relação com a questão da representação, mas que resultam igualmente na marginalização do conceito. Efectivamente, se a reflexão visa, num quadro que pressupõe a igualdade e a autonomia individual, levar o contratualismo liberal até aos limites da abstracção, como pretende Rawls, ou estabelecer, à maneira de Habermas, os parâmetros da comunicação racional entre indivíduos, pouco sentido faz abordar o 
fenómeno da representação, que, como sublinha Diogo Pires Aurélio, "se destina a legitimar uma supremacia, apesar da igualdade, de quem legisla sobre quem tem de obedecer"(1).

Contrariando esta secundarização do conceito, tem surgido ñas últimas décadas um corpo sólido de literatura que recoloca a representação no centro da teoria democrática. Trata-se, na verdade, de urna literatura muito variada, que aborda a questão da representação sob perspectivas assaz diversas. Certos autores têm reflectido sobre a dimensão eleitoral da representação democrática, trabalhando assuntos que, apesar de muito caros à ciência política, pouca atenção haviam tido no campo da teoria política: desenho constitucional (presidencialismo versus parlamentarismo); escolha do sistema eleitoral, verificando-se um forte consenso entre os teóricos quanto à superioridade, sob o ponto de vista da justiça eleitoral, da representação proporcional face aos sistemas maioritários(2); partidos políticos ${ }^{(3)}$. Outros têm focado a questão na óptica dos grupos minoritários ou marginalizados e dos obstáculos que se lhes deparam no acesso às esferas do poder(4). E há ainda alguns que têm procurado explorar alternativas não-eleitorais de representação democrática - uma representação democrática, por assim dizer, auto-autorizada -, tendo como arena privilegiada de reflexão a política internacional, onde não existem mecanismo eleitorais de autorização da representação(5).

(1) Diogo Pires Aurélio, "O que representam os representantes do povo", in Diogo Pires Aurélio (coord.), Representação Política. Textos Clássicos, Lisboa, Livros Horizonte, 2009, p. 12.

(2) Veja-se Kathleen L. Barber, A Right to Representation: Proportional Election Systems for the 21st Century, Columbia, Ohio University Press, 2001; Douglas J. Amy, Real Choices/New Voices: The Case for Proportional Representation Elections in the United States, Nova Iorque, Columbia University Press, 1995.

(3) Cf. Nancy Rosenblum, On the Side of the Angels: An Appreciation of Parties and Partisanship, Princeton, Princeton University Press, 2008.

(4) Ver Anne Phillips, The Politics of Presence, Oxford e Nova Iorque, Oxford University Press, 1995; Melissa S. Williams, Voice, Trust, and Memory: Marginalized Groups and the Failings of Liberal Representation, Princeton, Princeton University Press, 1998.

(5) Vide Margaret E. Keck e Kathryn Sikkink, Activists Beyond Borders: Advocacy Networks in International Politics, Ithaca, Cornell University Press, 1998; Andrew Kuper, Democracy Beyond Borders: Justice and Representation in Global Institutions, Oxford, Oxford University Press, 2004. 
Contudo, a tendência que se nos afigura mais estimulante nesta revalorização do conceito de representação em sede de teoria da democracia é aquela que, incluindo nomes como Claude Lefort(6), Frank Ankersmit( ${ }^{(7)}$ e David Plotke ${ }^{(8)}$, tem procurado sublinhar a natureza constitutiva da representação. $\mathrm{O}$ que estes autores têm vindo a afirmar, cada um à sua maneira, é que, longe de se reduzir a uma relação de delegação entre duas entidades previamente constituídas ${ }^{(9)}$

- representantes e representados -, a representação desempenha um papel na própria construção de comunidades e identidades políticas. Contrariamente ao que é pressuposto pela doutrina democrática clássica, de inspiração rousseauniana, o povo - ou, se quisermos, os representados - não é uma entidade prontamente identificável, possuidora de uma voz e de uma vontade próprias, cuja existência anteceda o fenómeno da representação. Bem pelo contrário, é através da representação que o povo primeiramente se constitui como sujeito político colectivo. Trata-se, pois, de um conceito que remete para o âmago do político, ou seja, para esse problema fundamental que é o da formação de um agregado que se atribui, de forma durável, uma identidade e uma vontade. Neste sentido, toda a política - e, nomeadamente, toda a política democrática que implique a constituição de um demos que exerça a soberania - pode e deve ser pensada em termos de representação(10).

Esta recente valorização do problema da representação na sua dimensão mais ampla não é, em todo o caso, uma novidade na história do pensamento político. Aliás, é interessante notar que, historicamente, a questão assume maior centralidade no debate teórico em contextos de

(6) Claude Lefort, L'Invention Démocratique, 2a ed., Paris, Fayard, 1994; Claude Lefort, Democracy and Political Theory, Oxford, Polity Press, 1988.

(7) Frank R. Ankersmit, Political Representation, Stanford, Stanford University Press, 2002.

(8) David Plotke, "Representation is Democracy", Constellations, vol. 4, n. ${ }^{\circ}$, 1997, pp. 19-34.

(9) Leitura que facilmente se extrai do influente estudo de Hanna Fenichel Pitkin, The Concept of Representation, Berkeley, Los Angeles e Londres, University of California Press, 1967.

aopara uma panorâmica dos vários debates em torno do conceito de representação na teoria democrática contemporânea, cf. Nadia Urbinati e Mark Warren, "The Concept of Representation in Contemporary Democratic Theory", Annual Review of Political Science, vol. 11, 2008, pp. 387-412. 
crise de legitimação do poder instituído. A vaga revolucionária de finais de setecentos foi um desses momentos: marcado, na América do Norte, pelas reflexões dos founding fathers e pelos debates entre federalistas e antifederalistas; e, em França, pelas discussões em torno do tiers état e da constituição da nação. $\mathrm{O}$ outro foi o da desagregação do Estado liberal na Europa de entre-guerras, com a fatídica experiência republicana da Alemanha de Weimar a surgir como caso extremo. A forma como a crise de Weimar foi pensada por Schmitt e Kelsen(11), a reflexão destes autores sobre os fundamentos do poder político, a natureza do Estado e a essência da democracia reserva um lugar de destaque ao conceito de representação e suas implicações mais profundas. E daí a urgência, no nosso entender, de a colocar em diálogo com os esforços teóricos mais recentes, na sua tentativa de pensar a democracia fora tanto do escopo descritivo e empiricista neoschumpeteriano, como do ideal moral da democracia cosmopolita de inspiração rawlsiana ou habermasiana.

\section{A representação nos fundamentos do Estado e da democracia: o que é o povo?}

Face a uma definição padrão de democracia como "governo do povo" ou "soberania popular"(12), levantam-se, de imediato, duas questões:

1. O que é o poder?

2. O que é o povo?

São questões eternas e incontornáveis. A primeira, respeitante à natureza do poder, é o denominador comum de todo o pensamento político. A segunda, que é aquela que pretendemos abordar aqui em detalhe, pergunta pela entidade que é suposto exercer o poder num certo

(11) Referindo apenas os autores cuja obra será objecto de análise no presente ensaio. $\mathrm{O}$ rol de nomes poderia, efectivamente, alargar-se a Hermann Heller, Gerhard Leibholz e demais teóricos - essencialmente juristas - que, nesse contexto, reflectiram com elevado grau de profundidade sobre o problema da representação.

(12) Não sendo, como é óbvio, universalmente aceite, trata-se de uma definição de uso corrente e assaz próxima das origens etimológicas do termo. 
tipo de regime político. O que tentaremos demonstrar, através da análise do pensamento de Schmitt e Kelsen, é que a construção dessa entidade não pode abdicar do conceito de representação.

Na obra de Carl Schmitt, é vã a busca por uma resposta clara à questão do povo. Como nota Mark Lilla(13), o conceito permanece vago nos escritos schmittianos. No entanto, apesar da inexistência de uma definição precisa, ele não deixa de constituir o esteio da teoria do Estado do jurista germânico. Com efeito, mesmo que ela não nos diga com clareza o que é o povo, diz-nos sem hesitação que existem povos e que o Estado nada mais é do que um povo no seu estádio de unidade política(14). O povo situa-se, pois, numa dimensão de existencialidade concreta, como que empiricamente dada, sobre a qual assenta a edificação política do Estado.

Schmitt distingue dois caminhos teoricamente possíveis para atingir e manter o estádio da unidade política. Por um lado, ele pode brotar directamente da vivência concreta do povo, potenciado, por exemplo, por uma forte homogeneidade cultural ou por fronteiras geográficas bem definidas. Nesse caso, é o princípio da identidade que preside à formação do Estado: o povo, entendido como realidade fáctica anterior ao Estado, identifica-se consigo próprio enquanto unidade política. Por outro lado, se partirmos da pressuposição de que a unidade política do povo nunca emerge enquanto identidade real e imediata, chegamos à conclusão de que terá de lhe ser dado corpo, de que alguém terá de a encarnar. E nesse caso, prevalece o princípio da representação.

Ora, na realidade, ambos os princípios são necessários para a formação da unidade política do povo. Apesar de opostos, não são mutuamente exclusivos. Pelo contrário, requerem-se um ao outro. A representação não pode operar como único princípio constitutivo do Estado, porquanto isso equivaleria a ignorar-se a presença fáctica e anterior do próprio povo. E desaparecendo o povo, desaparece o conteúdo do Estado. No sentido inverso, uma identidade absoluta do povo consigo próprio enquanto unidade política é também irrealizável.

$\left.\mathrm{d}^{3}\right)$ Mark Lilla, 'The Enemy of Liberalism", The New York Review of Books, vol. 44, n 8, 15 de Maio de 1997, consultado online, no dia 5 de Abril de 2012, in http: / / www.nybooks.com / issues /1997/ may /15 /.

(14)Carl Schmitt, Verfassungslehre, 10a ed., Berlim, Duncker \& Humblot, 2010, p. 205. 
Em boa verdade, nem uma democracia directa que possa reunir, num mesmo lugar, todos os cidadãos se livra da noção de representação. Isto porque a unidade política do povo não se esgotaria na assembleia popular - ela existiria, temporal como espacialmente, para além dela. Nesse sentido, a assembleia popular não poderia deixar de representar a unidade política do povo. Mas há mais: os populares reunir-se-iam não como pessoas privadas, em busca do seu interesse particular, mas como cidadãos, procurando favorecer o bem comum. Ou seja, surgiriam, tal qual os parlamentares das democracias modernas, como representantes de todo o povo. Na medida em que a unidade política necessita de forma, de ser concretizada de alguma maneira por instituições e, no limite, por pessoas, a ideia de representação afigura-se incontornável(15).

Essa necessidade decorre de uma exigência de publicidade. O Estado, enquanto forma política, requer representação porque precisa de se tornar visível. E a visibilidade só se alcança na esfera do que é público, do que acontece à vista de todos(16). Aqui, Schmitt acerca-se da duplicidade subjacente ao conceito de representação, que tem sido sublinhada pela generalidade dos autores que pensaram seriamente a questão(17). Em derradeira análise, representar significa tornar presente uma ausência, tornar visível o invisível - no caso vertente, o povo enquanto unidade política(18). O conceito remete, pois, para duas entidades autónomas e inassimiláveis: representantes e representados, sujeito e objecto da representação. $\mathrm{O}$ valor e a qualidade de um e do outro encontram-se em relação directa. Por um lado, só pode ser objecto de representação algo que seja capaz de uma existência pública e visível. Assuntos meramente privados encontram-se, portanto, excluídos. Nessa medida, a ideia de representação, no seu sentido propriamente político (Reprasentation), afasta-se da noção privatística de representação como mera delegação de interesses (Vertretung), com a qual é frequentemente confundida(19).

(15)Carl Schmitt, ob. cit., pp. 206-208 e 215.

(16) Ibidem, p. 208.

(17) Vide Hanna Fenichel Pitkin, ob. cit., pp. 8-9. No mesmo sentido, Diogo Pires Aurélio, ob. cit., pp. 13-14.

(18)Carl Schmitt, ob. cit., pp. 209-210.

(19) Schmitt serve-se, aqui, da distinção, que não encontra paralelo nas línguas românicas ou no inglês, entre o termo alemão de origem latina (Reprasentation) e o termo de génese germânica (Vertretung). 
É o povo enquanto unidade política, que se distingue, superando-a, da soma de individuos que o compõem, o objecto por excelencia da representação. Por outro lado, exige-se da personalidade do sujeito da representação uma autoridade e um valor próprios, que o coloquem à altura do palco da visibilidade(20).

Intimamente relacionado com a publicidade surge o princípio da independência. É bem evidente que a sujeição do representante a instruções imperativas privá-lo-ia do seu valor próprio, degradando-o à condição de agente ou comissário e retirando-lhe a capacidade de se impor na esfera pública. Mais do que uma função no Estado, o representante tem uma vontade e um poder próprios - é esse o seu traço distintivo. Apenas quem aje e decide autonomamente em nome do povo enquanto unidade política pode reclamar para si uma natureza representativa. Nesse sentido, Schmitt crê estar a seguir uma intuição hobbesiana fundamental: a de que é a representação que dota o Estado do seu elemento pessoal e volitivo, permitindo-lhe, assim, existir politicamente. Porque encontra a sua unidade na pessoa de um soberano, o Estado não é apenas um artifício, mas sim um artificio personificado ou uma pessoa artificial, possuindo, nessa medida, uma vontade - a vontade comum(21).

$\mathrm{Na}$ perspectiva da teoria pura do direito de Kelsen, o problema da formação do Estado é uma questão estritamente jurídica, que não remete, contrariamente ao que pretende Schmitt, para uma substância anterior (o povo), empiricamente dada. Se, para Schmitt, o Estado designa um povo no estádio de unidade política, para Kelsen, ele é a corporalização da unidade jurídica. Estado e ordem jurídica são uma e a mesma coisa; a criação do direito é a realização do Estado(22).

Para Kelsen, pois, o conceito de povo não é conatural ao conceito de Estado. Estado designa, tão-somente, a unidade da ordem normativa, que não pode ser colocada em causa por distinções qualitativas entre

(20)Cf. Carl Schmitt, Rômischer Katholizismus und politische Form, 5a ed., Estugarda, Klett-Cotta, 2008, pp. 35-36.

(21)Ver Carl Schmitt, Verfassungslehre, pp. 212-214.

(22) Entre as diversas passagens na obra do jurista austríaco em que essa identidade é afirmada, veja-se, por exemplo, Hans Kelsen, "Vom Wesen und Wert der Demokratie (1. Aufl. 1920)", in Hans Kelsen, Verteidigung der Demokratie, Tübingen, Mohr Siebeck, 2006, p. 11, nota 14, e p. 17. 
direito público e direito privado. Por conseguinte, Kelsen recusa a abordagem schmittiana que, a partir da distinção entre o termo alemão de origem latina (Repràsentation) e o de raiz germânica (Vertretung), trata a representação política como um fenómeno radicalmente distinto da representação no direito civil. Pelo contrário, aquela deixa-se reconduzir aos fundamentos desta última: representação significa que, através de uma disposição de direito positivo, a vontade do representante conta como a do representado. Dito de outro modo, a expressão da vontade do representante resulta no mesmo efeito jurídico que a expressão da vontade do representado produziria. Trata-se, em boa verdade, de uma situação excepcional, que contraria a regra geral, segundo a qual a expressão da vontade de alguém vincula o próprio, não outrem. Ora, é certo que, para determinadas categorias de pessoas (crianças, por exemplo), a excepção configura a regra. Ou seja: a expressão da própria vontade não produz jamais qualquer efeito jurídico; elas só podem exprimir uma vontade através dos seus representantes legais. Porém, nos restantes casos, a esmagadora maioria, em que a representação não é determinada por lei, ela só pode assentar na livre contratualização entre representado e representante. Damos, aqui, precedência ao representado sobre o representante, porque o contrato corresponde justamente ao momento em que aquele define as condições da representação. Na perspectiva de Kelsen, não faz sentido a ideia de que o representado possa exprimir, simplesmente, uma vontade genérica de ser representado, sem mais especificação. Bem pelo contrário, tem de determinar concretamente o âmbito da representação, pois esta figura jurídica deriva, no essencial, da impossibilidade fáctica, fruto de uma série de condicionantes (sobretudo, espaciais e temporais), de o representado produzir por si próprio certos efeitos jurídicos. $\mathrm{O}$ representante actúa, pois, nos estritos limites estipulados pelo representado(23).

A relação entre parlamento e povo que se pretende descrever sob a designação de representação teria, nessa medida, de ser análoga à relação entre representante e representado no direito privado. Tal designação seria, pois, pertinente, se uma norma positiva postulasse que, regra geral, as resoluções do povo têm o valor de leis, podendo, no entanto,

(23)Hans Kelsen, "Allgemeine Staatslehre", in Hans Kelsen, Verteidigung der Demokratie, Tübingen, Mohr Siebeck, 2006, pp. 37-40. 
em condições excepcionais, o parlamento tomar, no lugar do povo, resoluções de valor idéntico. Ora, em nenhuma das constituições das democracias ditas representativas se encontra tal norma. Contrariamente, o que nelas figura é o afastamento da participação directa do povo na legislação, a atribuição exclusiva do poder legislativo ao parlamento eleito pelo povo. Mais ainda: consagram a independência jurídica do parlamento face ao povo e a inadmissibilidade de instruções imperativas aos deputados. Aliás, a passagem das cortes pré-modernas para o parlamentarismo é justamente marcada pela abolição do mandato imperativo(24). Nessa medida, a ideia de representação do povo pelo parlamento, de que a vontade do parlamento deve valer como vontade do povo, encontra-se em contradição flagrante com a realidade do direito positivo. Neste, nada aponta para uma relação de representação entre parlamento e povo. Bem pelo contrário, a independência de um relativamente ao outro, dos deputados face aos eleitores denega precisamente o vínculo de subordinação que subjaz a toda a representação. É neste sentido eminentemente jurídico que Kelsen denuncia a "ficção da representação", que, contra a evidência do direito positivo, continua a ser ideologicamente sustentada pelo dogma político da soberania popular(25).

Ora, se falar em representação não tem cabimento, como é que o jurista austríaco define a relação entre povo e parlamento? Trata-se, essencialmente, de uma relação de criação entre dois órgãos do Estado. Ao povo, órgão primário, cabe a criação do parlamento, órgão secundário, através de uma eleição. Esta relação de criação entre órgão primário e órgão secundário não pode, todavia, ser confundida com uma relação de subordinação. Do facto de que o parlamento é eleito - criado - pelo povo não segue que aquele tenha de executar a vontade deste. Aliás, o povo de que aqui se fala não é o povo empiricamente dado, na sua inassimilável diversidade sociológica. É o povo enquanto construção jurídica, ou seja, enquanto conjunto de cidadãos com direito de voto. Nesse sentido, a única vontade que o povo pode exprimir é aquela que se manifesta no acto da eleição do parlamento e que resulta na sua composição,

(24) Kelsen faz notar que a expressão mandato livre encerra em si algo de contraditório, uma vez que a palavra mandato exprime a ideia de vínculo, não de independência.

(25)Hans Kelsen, ob. cit., pp. 41-43. 
a qual não se traduz, efectivamente, em nenhuma instrução específica quanto à actividade concreta do órgão eleito. A criação não implica uma subordinação e, por conseguinte, não funda uma representação do povo pelo parlamento(26).

Em todo o caso, dizer que o parlamento não representa o povo não quer dizer que tanto o parlamento como o povo não possam representar uma terceira entidade: o Estado. Com efeito, Kelsen fala de ambos como órgãos do Estado. Na verdade, o Estado só pode exprimir uma vontade e agir de acordo com ela através dos seus órgãos(27). Neste caso, contrariamente ao que sucedia na pretensa relação de representação entre parlamento e povo, não estamos perante uma ficção, mas sim perante uma construção jurídica. Nas palavras de Kelsen, "[a]lguém é órgão do Estado, representa o Estado, porque as suas acções 'valem' como acções do Estado, isto é, são imputadas através de uma norma ao Estado enquanto unidade da ordem [jurídica]" (tradução minha)(28). Neste sentido, parlamento e povo são em igual medida órgãos estatais, cada um deles representando o Estado nas suas respectivas e normativamente determinadas funções: o povo elegendo o parlamento; o parlamento legislando. Esta distinção funcional entre órgãos estatais deriva das exigências inelutáveis do "princípio diferenciador da divisão do trabalho, que é a condição de todo o progresso da técnica social"(29).

Ora, é seguramente possível, nos termos kelsenianos, pensar o Estado na ausência do conceito de povo, enquanto Estado autocrático. A democracia, contudo, implica a existência do povo como órgão do Estado. Porém, para Kelsen, o povo de que aqui se fala não é o povo na dimensão existencial, substantiva de que falava Schmitt. O povo que participa na formação da vontade legislativa do Estado democrático é

(26) Ibidem, p. 44.

(27)Ibidem, p. 36.

(28) Hans Kelsen, "Vom Wesen und Wert der Demoktratie (1. Aufl. 1920)", pp. 11-12, nota 14: "Jemand ist Organ des Staates, reprásentiert den Staat, weil seine Handlungen ais solche des Staates ,gelten', d. h. auf Grund einer Norm dem Staate ais der Einheit der Ordnung zugerechnet, auf die im Staate personifizierte Einheit des Normensystems bezogen werden".

(29) Hans Kelsen, "O problema do parlamentarismo", in Diogo Pires Aurélio (coord.), ob. cit., p. 155. 
um povo construido normativamente - e, como veremos mais à frente, também politicamente.

\section{Democracia e parlamentarismo: superação ou reforma?}

O parlamentarismo, ao contrário da democracia, não figura nas tradicionais distinções das formas de Estado. Historicamente, é um produto recente, configurando a exigência propriamente política do liberalismo, a sua forma de governo, limitada a montante pela consagração dos direitos fundamentais e pela separação dos poderes. Na perspectiva de Schmitt, trata-se de urna peculiar concatenação de noções de representação e de identidade e, mais concretamente, de elementos provenientes das formas monárquica, democrática e aristocrática de Estado. Afirma-se, pois, segundo o autor, como urna forma mista de Estado, exprimindo, nos seus matizes, a condição política do liberalismo, situada algures entre a negação do princípio da soberania absoluta do monarca e a assunção completa da soberania popular(30).

A crise do parlamentarismo corresponde, segundo Schmitt, ao soçobrar desse instável equilíbrio liberal, sob a pressão do princípio democrático da identidade. A este subjaz a ideia fundamental de igualdade. Não se trata, todavia, da igualdade natural de todos os seres humanos de que fala o individualismo liberal. Essa está na base dos direitos fundamentais, mas á, na sua essência, um princípio apolítico, na medida em que abole toda a possível distinção. A forma política requer, contudo, distinções, pelo que o princípio sobre o qual assenta a democracia é, não a igualdade geral e abstracta de todos os seres humanos, mas a igualdade que resulta da pertença comum a um determinado povo. A igualdade geral e abstracta, inalienável porque inscrita na natureza humana, é politicamente irrelevante. Propriamente política é a igualdade, no seio do Estado, entre cidadãos, não a igualdade, fora dele, entre seres humanos. O conceito democrático de igualdade é diferenciador, não nivelador: afirma-se por contraposição a uma desigualdade fundamental - entre iguais e não-iguais, entre cidadãos e estrangeiros. Trata-se, pois, de uma igualdade substancial que antecede e sustenta todas as igualdades formais que possam ser consagradas constitucionalmente:

(30)Carl Schmitt, ob. cit., pp. 216-219. 
a igualdade perante a lei, o sufrágio igual e universal, a igualdade no acesso a cargos públicos, etc. Nenhuma destas igualdades formais, consideradas isoladamente ou no seu conjunto, defíne a igualdade democrática. Inversamente, todas elas remetem para uma igualdade substancial que as precede: todos os cidadãos são iguais em direitos e deveres porque partilham de uma mesma substância. Coloca-se, então, a questão: onde jaz essa substância? Histórica como teoricamente, desde a Grécia antiga, a resposta a essa pergunta varia grandemente, mas, no seu cerne, deixa-se sempre reconduzir a um certo tipo de homogeneidade. Em termos teóricos, esta última foi levada ao paroxismo por Rousseau, que a concebe como a homogeneidade efectiva das vontades de todos os cidadãos: a volonté générale. Aquém da concepção de Rousseau, na realidade política, a homogeneidade passou a ser encontrada, a partir da Revolução Francesa, na Nação. A homogeneidade nacional erige-se, na modernidade, a sustentáculo substancial do Estado democrático(31).

Toda a dinâmica democrática conjuga-se para limitar o alcance do princípio da representação. É certo que este jamais pode ser plenamente denegado, sempre que se coloque o problema da forma política, da formação do Estado. No entanto, a pressão da identidade democrática pode, sem dúvida, chegar ao ponto de retirar ao parlamento a sua natureza representativa. Com efeito, o valor próprio dos parlamentares - fruto do mérito, da inteligência, da formação -, que sustenta a sua posição de independência, pode bem surgir aos olhos da igualdade democrática como um postulado inaceitável, na medida em que os coloca um palmo acima da homogeneidade substancial do povo. Na verdade, os argumentos em favor da democracia não deixaram nunca de assentar, nas palavras de Schmitt, numa "série de identidades [...]: identidade de governantes e governados, dominantes e dominados; identidade de sujeito e objecto da autoridade estatal; identidade do povo com a sua representação no parlamento; identidade do Estado e do povo votante em cada caso; identidade do Estado e da lei; por último, identidade do quantitativo (maioria numérica ou unanimidade) com o qualitativo (adequação da lei)"(32). Ora, entre todos estes pares conceptuais não existe

(31) Ibidem, pp. 223-231. No mesmo sentido, Carl Schmitt, "Democracia e parlamentarismo", in Diogo Pires Aurélio (coord.), ob. cit., pp. 186-192.

(32)Carl Schmitt, "Democracia e parlamentarismo", p. 201. 
uma identidade real. Segundo Schmitt, trata-se menos de identidades do que de "identificações"(33). A pressão da ideia democrática corresponde, pois, a um desejo activo de eliminar toda a duplicidade - entendida como desigualdade inaceitável - da realidade política. No limite, trata-se de uma pretensão vã, uma vez que condenada, à partida, a ficar aquém da identidade plena, imediatamente perceptível, presente e actuante: "[h]á sempre uma distância entre a igualdade real e o resultado da identificação"(34). Mas, a despeito dessa impossibilidade última, é esta a tendência subjacente à adopção de disposições que o autor considera típicas da democracia directa: a universalização do sufrágio, o princípio da proporcionalidade, o reconhecimento institucional dos partidos políticos, o encurtamento dos períodos eleitorais, as formas de iniciativa e consulta popular, entre outras. Face a ela, o parlamento, nas suas bases aristocráticas, surge como uma instituição caduca. A sua sobrevivência podia, é certo, continuar a assentar em considerações práticas, mas, no plano dos princípios, a desadequação relativamente às condições da moderna democracia de massas afigurava-se gritante. Abria-se, assim, o caminho para a superação do parlamentarismo liberal(35).

Também Kelsen, num dos raros aspectos em que a sua análise coincide com a de Carl Schmitt, vislumbra dinâmicas contraditórias na relação entre democracia e parlamentarismo liberal. $O$ triunfo histórico do parlamentarismo pôde, certamente, ser saudado como uma vitória do ponto de vista da ideia democrática, enquanto momento de superação do princípio monárquico. Contudo, cedo se percebeu também, apesar do trabalho legitimador da "ficção da representação", que ele constituía uma poderosa barreira ante a concretização de certos postulados de inspiração democrática. Para Kelsen, em todo o caso, esta tensão não assume os foros schmittianos de uma oposição metafísica que conduza

(33)Carl Schmitt, ob. cit., p. 201.

(34) Ibidem.

(35) Não espanta, pois, que os dois derradeiros capítulos do célebre ensaio de Schmitt sobre a condição histórico-intelectual do parlamentarismo sejam consagrados às alternativas ditatoriais (marxistas, anarquistas e fascistas) ao parlamentarismo - era nelas que o autor via a tendência do futuro. Cf. Cari Schmitt, Die geistesgeschichtliche Lage des heutigen P arlamentar ismus, 9a ed., Berlim, Duncker \& Humblot, 2010, p. 63 ss. 
inexoravelmente à dissolução do parlamentarismo. Trata-se, pelo contrário, da tensão entre um princípio instrumental, que decorre sobretudo da necessidade de divisão social do trabalho, e um princípio político-axiológico (a democracia), cuja raiz se encontra no pensamento da autodeterminação individual. Para o autor, o parlamentarismo, enquanto princípio instrumental, é suficientemente flexível para permitir uma concretização, se não absoluta pelo menos aproximada, do princípio político-axiológico da democracia.

Urge, num primeiro passo, esclarecer a forma como Kelsen deriva a democracia da ideia de liberdade, de autodeterminação individual. Politicamente, com efeito, a liberdade é um valor paradoxal. Ela constitui, simultaneamente, o horizonte inescapável de todo o pensamento político e a própria negação de tudo o que é político e de toda a ordem social. Em boa verdade, na sua acepção plena, a ideia de liberdade conduz à rejeição da possibilidade de imposição de uma vontade externa à vontade própria do indivíduo. $\mathrm{O}$ instinto natural do indivíduo consciente do seu próprio valor leva-o a considerar o peso da ordem social - da vontade objectiva que dela dimana - uma opressão inaceitável. Porquê estar sujeito e dever obediência a quem não é mais do que um homem como eu? Neste sentido, a ideia de liberdade equivale, muito simplesmente, à negação de toda a forma de dominação, ou seja, do próprio conceito de Estado. Nas palavras de Kelsen, a partir do momento em que "o tu deves do imperativo social seja complementado por um see o que quiseres da parte dos destinatários, toda a ordem perde o seu sentido social"(36) (tradução minha). Para que se possa falar em sociedade e, sobretudo, em Estado, tem que existir uma distinção possível entre o conteúdo da ordem vigente e o conteúdo das vontades dos indivíduos a ela sujeitos. A ideia de liberdade, para poder entrar na esfera política, precisa de sofrer uma transformação que a faça ir além do simples ser livre de dominação que constitui a sua pureza originária. Nesse processo, a liberdade natural da anarquia, da ausência de forma política, dará lugar à liberdade no quadro de uma forma específica de Estado - a democracia.

O princípio decisivo, sobre o qual assenta a liberdade democrática, é o princípio da maioria. Para que se perceba o seu alcance, importa

(36)Hans Kelsen, "Vom Wesen und Wert der Demokratie (1. Aufl. 1920)", p. 5: "wo das ,du sollst' des sozialen Imperativs bedingt wird durch ein ,wenn und was du willst' des Adressaten, verliert die Ordnung jeden sozialen Sinn". 
contrastá-lo com aquele que, aparentemente, remete de forma mais clara para a ideia de liberdade natural - a unanimidade. De facto, na sua teorização da fundação originária do Estado, os contratualistas clássicos, apesar de conceberem e justificarem esse acto fundamental de transição em termos muitos distintos, prevêem a unanimidade, a concordância geral das vontades dos contratantes. O contrato que institui a ordem social corresponde, não à vontade de uma maioria, mas à vontade de todos. A liberdade individual, no seu sentido mais profundo, encontra-se assim salvaguardada.

Ora, acontece que tal contrato originário é mera hipótese teórica. $\mathrm{Na}$ prática da experiência social, o que sucede é que o indivíduo nasce no seio de uma ordem estadual já instituída, em cuja fundação não participou e cujos imperativos lhe podem, muito naturalmente, surgir como a expressão de uma vontade externa contrária à sua vontade individual. Torna-se, pois, necessário admitir a possibilidade de uma diferença entre a vontade objectivamente válida - tornada norma, ordem - e as vontades dos indivíduos a ela sujeitos, sendo que o ponto é já não a fundação ex nïhïlo de uma nova ordem, mas antes a permanência ou mudança da ordem vigente. Neste caso, as limitações do princípio da unanimidade tornam-se por demais evidentes. Se, no contrato social originário, a exigência de unanimidade surgia como garantia da liberdade individual, a partir do momento em que já não se pode escapar ao alcance da ordem social e que a questão se limita à sua eventual modificação, ela torna-se num seu claro adversário. Na verdade, essa exigência levaria a que uma minoria - na hipótese extrema, a mais radical das minorias: um elemento - pudesse bloquear com sucesso a vontade de mudança da maioria. Neste contexto, o princípio da maioria - mais precisamente: da maioria absoluta - surge como a maior aproximação possível à ideia de liberdade. Face à impossibilidade de fazer com que o conteúdo da ordem vigente seja conforme à vontade de todos os que a ela estão sujeitos, o princípio da maioria garante, pelo menos, que aquele corresponde à vontade do maior número de indivíduos. A sua lógica é a do compromisso entre uma exigência de liberdade profundamente individualista e a existência de uma ordem social(37).

(37)Vide Hans Kelsen, "Allgemeine Staatslehre", pp. 55-59; "O problema do parlamentarismo", pp. 167-169; "Vom Wesen und Wert der Demokratie (1. Aufl. 1920)", pp. 5-7. 
A assunção do princípio da maioria não implica, contudo, que a democracia redunde numa dominação irrestrita da maioria sobre a minoria. Bem pelo contrário, "a maioria pressupõe, por definição, a existência de uma minoria e, por conseguinte, o direito da maioria pressupõe a igualdade de direito à existência de uma minoria"(38). A consagração de certos direitos fundamentais e inalienáveis nas constituições dos Estados democráticos constitui, justamente, uma das expressões mais significativas dessa protecção da minoria, na medida em que, perante as imposições da ordem social, o indivíduo é a mais vulnerável das minorias ${ }^{(39)}$. Por mais reduzida que seja, a minoria vê assim afirmado o seu direito de existir, em condições de igualdade, ao lado da maioria, podendo almejar, num futuro mais próximo ou longínquo, a transformar-se ela mesma em maioria. Por outro lado, no presente e enquanto tal, a própria existência da minoria influencia até certo ponto o comportamento da maioria, impedindo que as decisões maioritárias ignorem por completo os interesses da minoria. Se o direito da maioria resulta, em si mesmo, de um compromisso entre a ideia de liberdade e a necessidade de uma ordem social, a dualidade que lhe é inerente remete também ela para o compromisso, para o prosseguimento de uma via intermédia, conciliadora de interesses opostos. Nesta tendência para o compromisso reside o potencial de integração social do princípio da maioria(40).

Ora, o parlamentarismo é capaz de dar resposta satisfatória aos dois níveis de reflexão da teoria do Estado de Kelsen: o instrumental da teoria jurídica e o axiológico da teoria política. Na secção anterior, verificamos que o parlamento correspondia à necessidade de representação da vontade do Estado, o qual, enquanto sinónimo da unidade da ordem normativa, apenas pode agir e querer através dos seus diversos órgãos. O parlamento, como órgão legislativo do Estado, cuja função é produzir normas de carácter geral, satisfaz assim as exigências da divisão social do trabalho. Contudo, esta justificação eminentemente técnica não esclarece o porquê da pertinência de um órgão com as características do parlamento, isto é, de um órgão colegial eleito pelo povo. Ora, é jus-

(38)Hans Kelsen, "O problema do parlamentarismo", p. 169.

(39) Cf. Hans Kelsen, "Vom Wesen und Wert der Demokratie (1. Aufl. 1920)", p. 9.

(40) Ver Hans Kelsen, "Allgemeine Staatslehre", p. 58; "O problema do parlamentarismo", pp. 169-170. 
tamente aqui que entronca a teoria kelseniana da democracia, assente no princípio da maioria como aproximação possível à ideia originária de autodeterminação individual. Para além da função de mediação, o parlamento permite igualmente a operacionalização do princípio da maioria. De facto, por um lado, a sua composição é expressão de uma vontade maioritária que não só tolera como exige a presença de uma minoria, ao passo que, por outro lado, "o procedimento especificamente contraditório-dialéctico"(41) que nele tem lugar, antecedendo a tomada de decisões, possibilita o ajuste, o compromisso entre maioria e minoria.

Contudo, isso não quer dizer que o parlamentarismo deva ser entendido à luz dos moldes liberais oitocentistas. Bem pelo contrário, segundo Kelsen, afigura-se urgente uma reforma que promova a sua democratização. E essa reforma consiste, fundamentalmente, em trazer os partidos políticos para a esfera do Estado(42). De facto, tomando como ponto de partida a construção jurídica do povo enquanto conjunto de cidadãos com direito de voto, pode dizer-se que os partidos operam a construção política do povo, associando cidadãos activos que comungam das mesmas ideias ou interesses, para lhes assegurar uma efectiva influência no processo político ${ }^{(43)}{ }^{44}$. Na verdade, para Kelsen, a democracia real e possível é, necessariamente, um "Estado de partidos" $m$.

O não reconhecimento dos partidos políticos por parte da doutrina dominante no direito público germânico da época não exprimia, segundo Kelsen, um antagonismo dirigido unicamente contra essas forças políticas. Mais do que isso, tratava-se de uma oposição à própria democracia. Efectivamente, os doutrinários anti-partidos, entre os quais se incluíam Heinrich Triepel(45) e o próprio Carl Schmitt, argumentavam que a natureza do partido político é contrária à natureza do Estado. Os partidos, enquanto portadores de interesses particulares e de

${ }^{(41)}$ Hans Kelsen, "O problema do parlamentarismo", p. 170.

(42) Hans Kelsen, "Vom Wesen und Wert der Demokratie (2. Aufl. 1929)", in Hans Kelsen, Verteidigung der Demokratie, Tübingen, Mohr Siebeck, 2006, p. 167.

${ }^{(43)}$ Cf. Hans Kelsen, ob. cit., pp. 165-166.

(44) Ibidem, p. 167.

(45) Reitor da Faculdade de Direito de Berlim e autor de um opúsculo sobre a constituição e os partidos políticos (Die Staatsverfassung und die politischen Parteien) que Kelsen toma como típica manifestação da atitude anti-partidos que grassava entre os publicistas alemães. 
identidades parciais, não podiam constituir o fundamento de uma entidade que se pretende afirmar como uma unidade que supera tais interesses e identidades. Ora, para Kelsen, a existência aprioristica de um interesse geral unificador, situado acima das fracturas confessionais, nacionais ou de classe (ou outras), constitui uma ilusão metapolítica. Na sua perspectiva, se a vontade legislativa do Estado não deve exprimir apenas o interesse ou a concepção do mundo de um determinado grupo, não subsiste outra alternativa que não seja a que a faça resultar do compromisso entre interesses e concepções opostas. A organização do povo em partidos políticos cria justamente as condições para que esse compromisso possa ser atingido. A democracia enquanto Estado de partidos, na medida em que faz brotar a vontade do Estado do ajuste possível entre posições divergentes, pode assim abdicar da ficção de uma vontade geral suprapartidária. $\mathrm{Na}$ verdade, o que resulta desta leitura de Kelsen, em marcado contraste com a de Cari Schmitt, é a recusa de uma concepção do povo como potência política preexistente. É no próprio processo de democratização, através da integração dos cidadãos em partidos políticos, da competição eleitoral entre estes e, finalmente, da discussão em sede parlamentar, que se forma esse sujeito político colectivo que usualmente designamos por povo(46).

\section{De Weimar para o presente: recuperando as dimensões colectiva e agonística da política democrática}

Reflectir sobre a eventual actualidade do debate Schmitt versus Kelsen implica ter uma perspectiva quanto às tendências predominantes na teoria democrática contemporânea. A nosso ver, com efeito, esta encontra-se ainda dominada por um individualismo restritivo que nos conduz a menosprezar, se não mesmo a ignorar, os problemas da representação e da formação de um sujeito político colectivo. E possível distinguir, conforme notámos atrás(47), duas variantes assaz diversas desse individualismo. Por um lado, próxima da ciência económica, a visão da democracia como sistema de agregação de preferências individuais, desenvolvida por

(46) Hans Kelsen, "Vom Wesen und Wert der Demokratie (2. Aufl. 1929)", pp. 170-172.

(47) Vide supra, p. 3 deste artigo. 
autores como Joseph Schumpeter(48) e Anthony Downs(49), que adquiriu um estatuto quase paradigmático no campo da ciência política. Por outro lado, recentrando o debate no plano da ética e da filosofia moral, a teoria da justiça de John Rawls(50) e a teoría do agir comunicacional de Jürgen Habermas(51), entretanto expandidas e revistas por múltiplos seguidores. Não querendo colocar em causa os méritos destas duas linhagens de pensamento, julgamos, em todo o caso, que o individualismo que lhes subjaz - seja o do homo economicus que procura maximizar a utilidade, seja o do sujeito moral autónomo em busca de uma razão universal não permite dar satisfatoriamente conta da dimensão supra-individual da política e da questão, incontornável para o pensamento democrático, da constituição do povo, de um sujeito político colectivo.

De entre os pensadores políticos que despontaram na Europa de entre-guerras, Carl Schmitt tem sido o mais intensamente revisitado pelos teóricos contemporáneos que procuram alternativas a esse individualismo. Das várias reinterpretações recentes do pensamento do jurista germánico, parece-nos particularmente pertinente, no contexto desta reflexão, destacar a que inspira o modelo de democracia pluralista e agonística proposto pela filósofa belga Chantal Mouffe. Recuperando algumas das mais relevantes teses schmittianas, Mouffe reflecte sobre a tensão entre democracia e liberalismo, sublinhando como os principios democráticos da igualdade, da identidade entre governantes e governados e da soberania popular podem entrar em conflito com os valores liberais do primado do direito, dos direitos humanos universais e do respeito pela liberdade individual. Para a autora, é justamente a articulação, muitas vezes paradoxal, entre estes dois universos de ideias que caracteriza a condição da democracia moderna(52). Explorando a lógica democrática de inclusão-exclusão que subjaz à concepção

(48)Joseph Schumpeter, Capitalism, Socialism and Democracy, Nova Iorque, Harper and Bros., 1942.

(49) Anthony Downs, An Economic Theory of Democracy, Nova Iorque, Harper, 1957.

(50)john Rawls, A Theory of Justice, Oxford, Clarendon Press, 1972.

(51) Jürgen Habermas, Theorie des kommunikativen Handelns, 2 vols., Frankfurt am Main, Suhrkamp, 1981.

(52) Vide Chantal Mouffe, The Democratic Paradox, Londres e Nova Iorque, Verso, 2005, p. 3 ss. 
schmittiana da igualdade - fundada na distinção entre iguais e não-iguais, entre cidadãos e estrangeiros - e articulando-a com a distinção entre amigo e inimigo que, para o jurista alemão, é o critério fundamental do político, Mouffe crê poder operar uma revitalização agonística das democracias contemporâneas ${ }^{(53)}$.

No entanto, para que o seu modelo seja, a um tempo, agonístico e pluralista, Mouffe vê-se forçada a recusar as consequências últimas da reflexão schmittiana. Efectivamente, o único pluralismo que Schmitt admitia era um pluralismo de Estados, isto é, de povos no estádio de unidade política. Como o autor refere numa passagem de $\mathrm{O}$ Conceito do Político, é "[o] Estado como unidade política organizada que toma, como um todo e para si, a decisão sobre quem é amigo e quem é inimigo [ ] ]"(54) (tradução minha). Na esfera interna, pelo contrário, o pluralismo conduziria inevitavelmente à desagregação da unidade política do povo. Justamente por esse motivo, Schmitt via no multipartidarismo de massas, no qual degenerou o parlamentarismo clássico oitocentista, a expressão da dissolução do liberalismo, não da sua superação. Organizando-se em tomo de profundas clivagens sociais, os partidos políticos, para Schmitt, radicalizam-nas para lá dos limites da unidade do Estado.

Ao transpor a distinção amigo-inimigo para o plano interno, Mouffe está explicitamente a 1er Schmitt contra Schmitt. Na nossa perspectiva, o que se afigura mais interessante nessa recusa do "falso dilema de Schmitt"(55) é tratar-se, em derradeira análise, da recusa da sua concepção aprioristica do povo. Mouffe sublinha, com razão, que a distinção política fundamental entre amigo e inimigo de que fala Schmitt repousa, na verdade, numa distinção anterior, entendida como facto empiricamente dado, entre diversos povos. A dimensão schmittiana do político, longe de constituir esfera autónoma da experiência humana, limita-se a reconhecer fronteiras preexistentes, definidas rigidamente pela natureza ou pela história.

(53) Cf. Chantal Mouffe, ob. cit., pp. 37-45 e 49-53.

(54) Carl Schmitt, Der Begriff des Politischen, Munique e Leipzig, Duncker \& Humblot, 1932, p. 17: "Innerhalb des Staates ais einer organisierten politischen Einheit, die ais Ganzes fiir sich die Freund-Feindentscheidung trifft [...]".

(55) Vide Chantal Mouffe, ob. cit., p. 53. 
Ora, esta conclusão é plenamente suportada pela leitura que fizemos da teoría do Estado de Schmitt, a qual nos permite afirmar que a unidade política de um povo, atingida por via de urna certa articulação entre os princípios da identidade e da representação, repousa necessariamente numa homogeneidade substancial que remete para o reconhecimento de fronteiras preexistentes. Nesse sentido, a divisão e o antagonismo, porque irreconciliáveis com a referida homogeneidade, têm forçosamente de ser remetidos para o plano externo, para fora dos limites da unidade estadual.

Face à natureza restritiva do pluralismo schmittiano - um pluralismo de Estados que não admite pluralismo no seio do Estado - a alternativa kelseniana parece-nos assaz frutuosa. Kelsen, de facto, oferece-nos uma resposta diferente à questão, fundamental para uma teoria da democracia, que é a de saber o que é o povo, essa entidade que é suposto exercer a soberania. Ao contrário de Schmitt, Kelsen não crê que a resposta nos possa ser dada pela natureza ou pela história, sob a forma de uma homogeneidade substancial. Para Kelsen, o povo é uma construção jurídica e política. E essa construção assenta num pressuposto relativista e, consequentemente, pluralista. Isto é: como não há forma de determinar, com absoluta certeza, o que é o bem, a verdade ou a justiça, em democracia renuncia-se à busca de um consenso plenamente inclusivo, que mais não seria do que uma ilusão metapolítica. A vontade do Estado democrático resulta, pois, do compromisso possível entre posições políticas divergentes e, eventualmente, irreconciliáveis. Como é próprio de uma atitude relativista, não se exige a nenhuma das partes que abdique, no final, da sua posição, ou que altere em alguma medida a sua leitura do problema em questão. A decisão normativa que brota da negociação e da discussão parlamentar corresponde ao ajuste possível entre as diversas posições partidárias, não coincidindo, provavelmente, em absoluto com nenhuma delas e, sobretudo, não reclamando para si um valor acrescido de verdade. É assim, com efeito, que Kelsen concebe a democracia como um Estado de partidos.

Este pluralismo relativista de Kelsen permite-nos recuperar as dimensões colectiva e agonística da política democrática. As intuições schmittianas nesse sentido, ainda que aparentemente estimulantes, acabaram, como vimos, por revelar-se enganadoras. A construção da unidade política do povo, por via dos princípios da identidade e da representação, assenta, afinal, numa distinção apriorística entre povos 
substancialmente homogéneos. A formação do Estado limita-se, pois, a conferir existencia política a um agregado preexistente, cujos contornos Schmitt deixa sempre na penumbra. E o pluralismo schmittiano, enquanto pluralismo de Estados, isto é, de povos no estádio de unidade política, não é apropriável por uma teoria da democracia, urna vez que se revela incapaz de conceber divisões no seio dessa unidade.

Ora, a teoria do Estado de Kelsen parece-nos sublinhar com acuidade a dimensão colectiva e intrinsecamente representativa da política democrática. É certo que o pensamento político do autor se funda na ideia de liberdade, de autodeterminação individual. Esta liberdade entendida como o direito do indivíduo de ser o único legislador de si próprio está, efectivamente, na base da ficção a-histórica do contrato social original. Contudo, na prática da vida política, ela conduziria à rejeição do Estado, uma vez que a experiência do indivíduo é a de ser membro de uma ordem já instituída, de cujo alcance não pode escapar, não a de ser parte de um contrato que, em boa verdade, nunca existiu. A liberdade dita natural - cuja presença, em todo o caso, não deixa de se fazer sentir nos direitos inalienáveis inscritos nas constituições democráticas - incorre, pois, numa transformação que a faz ir ao encontro da sua dimensão colectiva e representativa. A liberdade política, que Kelsen identifica com a democracia, é a liberdade de um povo soberano. E este precisa de ser representado, de modo a que, nas palavras de Diogo Pires Aurélio, "o conjunto deixe de ser uma simples abstracção e possa, de facto, decidir e agir enquanto todo",(56).

Julgamos que o pensamento de Kelsen, neste aspecto, se situa assaz próximo dos autores contemporâneos que têm sublinhado a natureza constitutiva da representação. Tanto a concepção, no plano estritamente jurídico, do povo e do parlamento enquanto órgãos do Estado, como a reflexão, no quadro da discussão em torno da reforma do parlamentarismo, sobre a natureza e função dos partidos políticos remetem, em última análise, para o problema da formação de um sujeito político colectivo, possuidor de uma identidade e de uma vontade. Esta dimensão colectiva da política democrática vem recolocar no foco da atenção teórica o conceito de representação. ${ }^{56}$ 
À dimensão colectiva importa, por fim, juntar a agonística. Esta reside, quanto a nós, na concepção kelseniana da democracia como Estado de partidos. Como tivemos a oportunidade de demonstrar, o Estado de partidos assenta no pressuposto relativista de que o conhecimento absoluto do bem, da verdade e da justiça é inacessível ao entendimento humano, pelo que não há forma de derivar a vontade comum de uma razão à qual todos se tenham de submeter. O Estado de partidos constrói o povo de forma intrinsecamente plural e adversarial, através do confronto, negociação e compromisso entre visões partidárias divergentes do bem comum. Trata-se, pois, de uma concepção do poder político que assume plenamente a sua indeterminação fundacional, a ausência de uma autoridade transcendental à qual possa apelar para legitimar as suas decisões. Kelsen exprime este aspecto nos termos, que hoje se nos afiguram porventura algo crus, da oposição entre uma visão do mundo metafísico-absolutista, na qual assentam todas as autocracias, e uma disposição crítico-relativista, que está na base da democracia(57). Em todo o caso, apesar dessa crueza e da proximidade por ela revelada a um positivismo entretanto caído em desuso, cremos que Kelsen não está substantivamente muito longe da caracterização que Claude Lefort faz da sociedade democrática como uma sociedade que não possui a sua própria definição, onde o poder é um "lugar vazio" e que reconhece, por isso, a existência de conflito e divisão(58).

A forma como Kelsen concebe o conflito que é constitutivo da política democrática peca, no entanto, por ser restritivamente institucionalista e pela excessiva esperança depositada na capacidade dos partidos políticos operarem como que uma síntese virtuosa entre sociedade e Estado. É certo que o jurista austríaco estava ao corrente dos fenómenos de natureza oligárquica que marcavam a vida interna dos grandes partidos, revelados sobretudo pelos estudos de Robert Michels(59), mas considerava que aqueles resultavam, em boa medida, da estrutura

(57) Vide Hans Kelsen, "Vom Wesen und Wert der Demokratie (2. Aufl. 1929)", pp. 223-228.

(58) Cf. Claude Lefort, L'Invention Démocratique, 2a ed., Paris, Fayard, 1994, p. 29; Claude Lefort, Democracy and Political Theory, Oxford, Polity Press, 1988, p. 19.

(59) Robert Michels, Zur Soziologie des Parteiwesens in der Modernen Demokratie, Leipzig, Werner Klinkhardt, 1911. 
juridicamente indefinida das organizações partidárias, pelo que a integração dos partidos na esfera estadual poderia, com maior ou menor dificuldade, democratizá-los internamente(60). Retrospectivamente, é fácil considerar tal optimismo infundado. Porém, do ponto de vista teórico, mais interessante do que fazer notar que a prática frustrou as melhores expectativas de Kelsen, é apontar para os limites estritos nos quais a democracia concebida como Estado de partidos encerra o pluralismo agonístico e a atitude relativista que lhe subjaz. Com efeito, Kelsen parece crer que o sistema representativo que o Estado de partidos institucionaliza é capaz de incluir no seu seio todos os interesses, valores, visões do mundo e identidades existentes na sociedade - uma suposição que importa questionar.

Para o fazer, vale a pena recuperar aqui a concepção schmittiana da igualdade democrática. Como vimos, para Schmitt, a igualdade que caracteriza a democracia é a que resulta da pertença a uma dada comunidade política, não a que remete para o conceito universalista de humanidade. Tem, pois, na sua base uma desigualdade fundamental que separa os que pertencem dos que não pertencem, que distingue cidadãos de estrangeiros. Esta dialéctica democrática de inclusão-exclusão, que Chantal Mouffe sublinha com pertinência, deve, quanto a nós, ser estendida a todo o processo representativo de formação de uma identidade e de uma vontade comuns. A construção do povo através de um dado conjunto de instituições representativas, e ainda que estas sejam intrinsecamente plurais e adversaríais como é o caso do Estado democrático de partidos, não consegue eliminar por completo a exclusão. No limite, haverá sempre vozes cuja voz do povo instituído não faz ouvir. Isto porque a construção de um nós que, num dado momento, quer e fala pelo povo implica a existência, nas suas margens, de um eles que não encontra lugar na configuração institucional vigente e que a questiona e contesta a partir de for $a$. Vários teóricos têm procurado reflectir sobre esta fronteira difícil da democracia representativa, através de conceitos como os de poder negativo do povo(61), contra-política, contra-democracia(62)

mVide Hans Kelsen, ob. cit., pp. 172-173.

(61) Nadia Urbinati, Representative Democracy: Principles and Genealogy, Chicago, University of Chicago Press, 2006, p. 29 ss.

(62) Pierre Rosanvallon, La Contre-Démocratie: La Politique à l'Âge de la Défiance, Paris, Seuil, 2006. 
e contra-representação(63), bem como da distinção entre um povo que é anterior à própria ordem institucional, um povo que é construído no seio da constituição democrática vigente e um povo que, inevitavelmente, persiste nas margens desta última(64). Na nossa perspectiva, o que importa frisar é que esse elemento refractário não deve ser concebido como o inimigo schmittiano, mas sim como o mais radical dos adversários políticos legítimos, aquele que conduz a lógica pluralista e agonística da política democrática às suas últimas consequências e cuja oposição é tão preciosa e necessária quanto a ordem representativa vigente, na qual não se revê.

\section{Conclusão}

Este ensaio procura contribuir para a reflexão em curso sobre o problema da representação no quadro do pensamento democrático. Após um longo período em que a representação foi remetida para um plano secundário pelo predomínio ora do pluralismo de agregação de preferências individuais, orientado pelo paradigma do homo economicus, ora do ideal metapolítico de um consenso moral plenamente racional e plenamente inclusivo, nas últimas décadas o conceito tem sido de novo valorizado em sede de teoria da democracia. Como parte dessa tendência recente, certos autores têm destacado a natureza constitutiva da representação, ou seja, o papel incontornável que o conceito desempenha na própria definição de identidades e comunidades políticas e, nomeadamente, na construção do povo como sujeito político colectivo. Tal reconceptualização vem tornar pertinente a releitura de dois autores clássicos do período entre-guerras, Carl Schmitt e Hans Kelsen, cujas reflexões sobre o Estado e a democracia reservam igualmente um lugar de relevo à questão da representação. A reconstrução do pensamento desses dois autores foi levada a cabo em dois momentos. No primeiro, remontamos aos fundamentos da teoria do Estado, para ir

(63) Vide Ernesto Laclau, On Populist Reason, Londres e Nova Iorque, Verso, 2005 , p. 83 ss.

(64) Veja-se, a este respeito, Andreas Kalyvas, Democracy and the Politics of the Extraordinary: Max Weber, Carl Schmitt and Hannah Arendt, Cambridge, Cambridge University Press, 2008. 
ao encontro do justo alcance do conceito de representação. No segundo, vimos como essas posições teóricas se traduziram no debate em torno da relação entre democracia e parlamentarismo. Esta releitura, que não deixou de salientar as aporias e limitações do pensamento de ambos os autores - principalmente, de Schmitt -, permitiu-nos redescobrir as dimensões colectiva e agonística da política democrática, que são aquelas que uma abordagem sob a óptica do problema da representação consegue trazer à evidência com maior intensidade. Tendo sublinhado a centralidade dessas duas dimensões, resta-nos, enfim, notar que a teoria política tem ainda um longo caminho de reflexão pela frente rumo a uma melhor compreensão da natureza do povo como sujeito político colectivo e do alcance e limites do conflito em contexto democrático - esperando, em todo o caso, que este ensaio constitua um modesto contributo nesse sentido.

\section{Bibliografia}

AMY, Douglas J., Real Choices/New Voices: The Case for Proportional Representation Elections in the United States, Nova Iorque, Columbia University Press, 1995.

ANKERSMIT, Frank R., Political Representation, Stanford, Stanford University Press, 2002.

AURÉLIO, Diogo Pires, "O que representam os representantes do povo", in Diogo Pires Aurélio (coord.), Representação Política. Textos Clássicos, Lisboa, Livros Horizonte, 2009.

BARBER, Kathleen L., A Right to Representation: Proportional Election Systems for the 21 ${ }^{\text {st }}$ Century, Columbia, Ohio University Press, 2001.

DOWNS, Anthony, An Economic Theory of Democracy, Nova Iorque, Harper, 1957.

HABERMAS, Jürgen, Theorie des kommunikativen Handelns, 2 vols., Frankfurt am Main, Suhrkamp, 1981.

KALYVAS, Andreas, Democracy and the Politics of the Extraordinary: Max Weber, Carl Schmitt and Hannah Arendt, Cambridge, Cambridge University Press, 2008.

KECK, Margaret E.; SIKKINK, Kathryn, Activists Beyond Borders: Advocacy Networks in International Politics, Ithaca, Cornell University Press, 1998. 
KELSEN, Hans, "Vom Wesen und Wert der Demokratie (1. Aufl. 1920)", in Hans Kelsen, Verteidigung der Demokratie, Tübingen, Mohr Siebeck, 2006, pp. 1-33.

KELSEN, Hans, "Allgemeine Staatslehre (1925)", in Hans Kelsen, Verteidigung der Demokratie, Tübingen, Mohr Siebeck, 2006, pp. 34-114 (excertos).

KELSEN, Hans, "O problema do parlamentarismo (1925)", in Diogo Pires Aurélio (coord.), Representação Politica. Textos Clássicos, Lisboa, Livros Horizonte, 2009, pp. 151-175.

KELSEN, Hans, "Vom Wesen und Wert der Demokratie (2. Aufl. 1929)", in Hans Kelsen, Verteidigung der Demokratie, Tübingen, Mohr Siebeck, 2006, pp. 149-228.

KUPER, Andrew, Democracy Beyond Borders: Justice and Representation in Global Institutions, Oxford, Oxford University Press, 2004.

LACLAU, Ernesto, On Populist Reason, Londres e Nova Iorque, Verso, 2005.

LEFORT, Claude, LTnvention Démocratique (1981), 2a ed., Paris, Fayard, 1994.

LEFORT, Claude, Democracy and Political Theory, Oxford, Polity Press, 1988.

LILLA, Mark, "The Enemy of Liberalism", The New York Review of Books, vol. 44, n. ${ }^{\circ}$ 8,15 de Maio de 1997, consultado online, no dia 5 de Abril de 2012, in http: / / www.nybooks.com /issues /1997/may /15 /.

MICHELS, Robert, Zur Soziologie des Parteiwesens in der Modernen Demokratie, Leipzig, Werner Klinkhardt, 1911.

MOUFFE, Chantal, The Democratic Paradox, Londres e Nova Iorque, Verso, 2005.

PHILLIPS, Anne, The Politics of Presence, Oxford e Nova Iorque, Oxford University Press, 1995.

PITKIN, Hanna Fenichel, The Concept of Representation, Berkeley, Los Angeles e Londres, University of California Press, 1967.

PLOTKE, David, "Representation is Democracy", Constellations, vol. 4, n. ${ }^{\circ} 1,1997$, pp. 19-34.

RAWLS, John, A Theory of Justice, Oxford, Clarendon Press, 1972.

ROSANVALLON, Pierre, La Contre-Démocratie: La Politique à l'Âge de la Défiance, Paris, Seuil, 2006.

ROSENBLUM, Nancy, On the Side of the Angels: An Appreciation of Parties and Partisanship, Princeton, Princeton University Press, 2008. 
SCHMITT, Carl, Die geistesgeschichtliche Lage des heutigen Parlamentarismus (1923), 9a ed., Berlim, Duncker e Humblot, 2010.

SCHMITT, Carl, "Democracia e parlamentarismo" (1923), in Diogo Pires Aurélio (coord.), Representação Politica. Textos Classicos, Lisboa, Livros Horizonte, 2009, pp. 177-206. (Tradução portuguesa da Nota prévia à 2a ed. (1926), da Introdução e do Capítulo I de Die geistesgeschichtliche Lage des heutigen Parlamentarismus).

SCHMITT, Carl, Rõmischer Katholizismus und politische Form (1923), $5^{\text {a }}$ ed., Klett-Cotta, 2008.

SCHMITT, Carl, Verfassungslehre (1928), 10ª ed., Berlim, Duncker \& Humblot, 2010.

SCHMITT, Carl, Der Begriffdes Politischen, Munique e Leipzig, Duncker \& Humblot, 1932.

SCHUMPETER, Joseph, Capitalism, Socialism and Democracy, Nova Iorque, Harper and Bros., 1942.

URBINATI, Nadia, Representative Democracy: Principles and Genealogy, Chicago, University of Chicago Press, 2006.

URBINATI, Nadia; WARREN, Mark E., "The Concept of Representation in Contemporary Democratic Theory", Annual Review of Political Science, vol. 11, 2008, pp. 387-412.

WILLIAMS, Melissa S., Voice, Trust, and Memory: Marginalized Groups and the Failings of Liberal Representation, Princeton, Princeton University Press, 1998. 